\title{
涟H90
}

\section{La minería, factor determinante del paisaje en Sierra Morena}

Francisco José Aute Navarrete | consultor de patrimonio industrial y periodista

URL de la contribución <www.iaph.es/revistaph/index.php/revistaph/article/view/3782>

\section{RESUMEN}

Entre las muchas causas que pueden alterar o incluso modificar de manera radical la natural perspectiva del paisaje de una zona o comarca, determinando además necesariamente sus itinerarios, la más importante de ellas ha sido sin duda la minería y sus inseparables compañeros los ferrocarriles.

No deja de ser admirable que haya sido la mano del hombre la que en apenas dos milenios haya incidido de manera tan categórica en la modelación del paisaje; baste recordar cómo sin necesidad de explosivos los romanos ya sabían hacer volar montañas, la ruina montium, y llevar a cabo ingentes movimientos de tierras en volúmenes que apenas si han sido superados en las últimas décadas del siglo XX.

La Sierra Morena es un macizo antiguo suavizado por millones de años de erosión y lances hidrológicos que se deshace en la gran plenillanura fluvial del Guadalquivir. Rica en toda clase de minerales útiles al hombre como pocas otras regiones, es un claro ejemplo de la interacción del hombre en el paisaje modificándolo a veces en proporciones desmesuradas y a veces esterilizándolo. En otras muchas ocasiones son los testimonios remotos de la minería ya asimilados al paisaje quienes nos informan del modo de vida de quienes beneficiaban los yacimientos y placeres someros dejándonos además numerosos testimonios arqueológicos de su utilería, sus conocimientos minero-metalúrgicos, y de sus creencias religiosas y prácticas fúnebres.

Por todo esto Sierra Morena hoy no es concebible sin una minería que horadó sus entrañas hasta ayer mismo haciéndola referente de riqueza en todo el mediterráneo.

\section{Palabras clave}

Córdoba (provincia) | Metalurgias | Minas | Minería | Paisajes | Patrimonio minero | Ossa-Morena | Sierra Morena | 


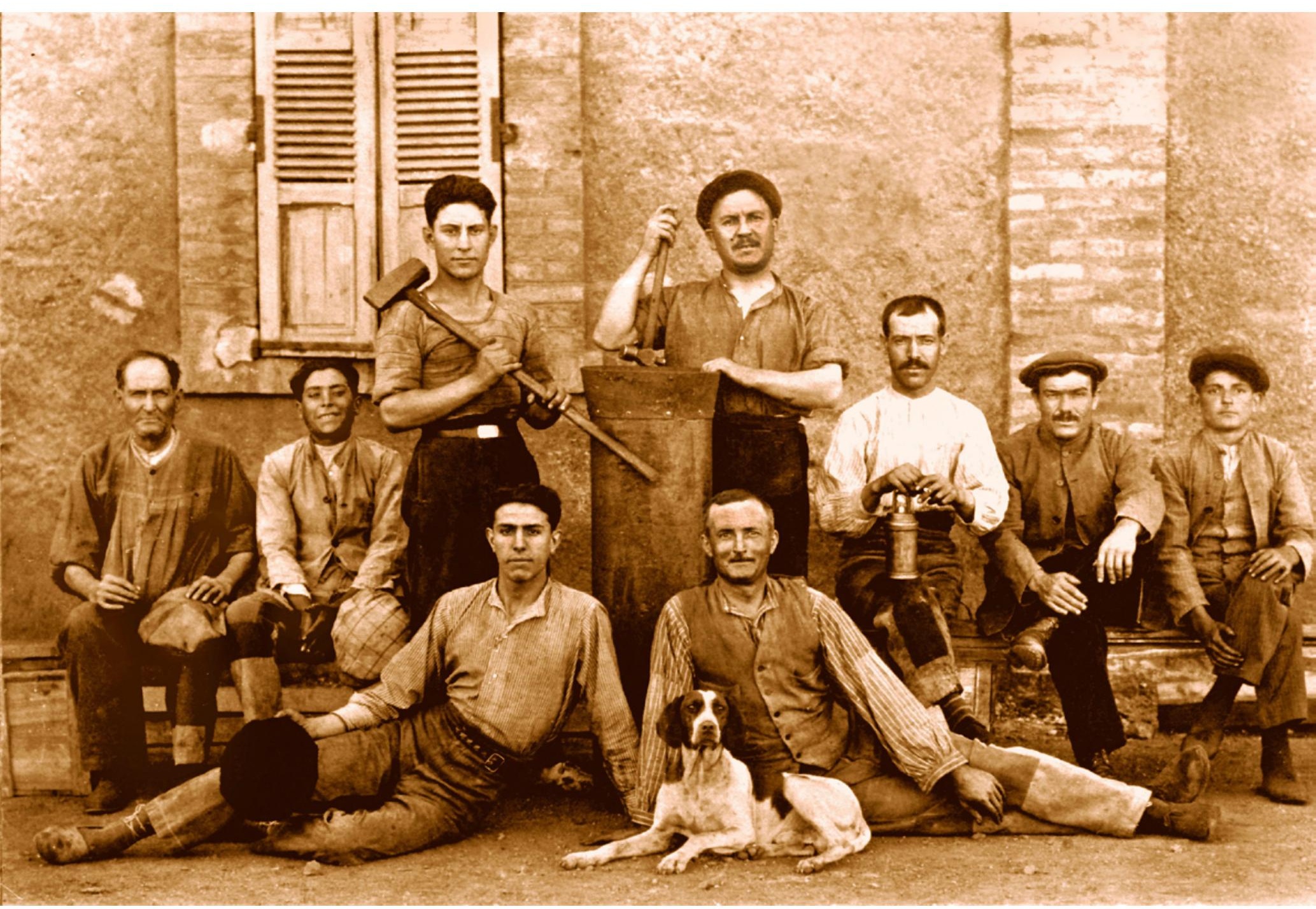

Trabajadores de las fraguas y talleres de la mina Santa Rosa en agosto de 1925. Pueblonuevo del Terrible (Córdoba) | fuente Archivos del autor (Anónimo) 


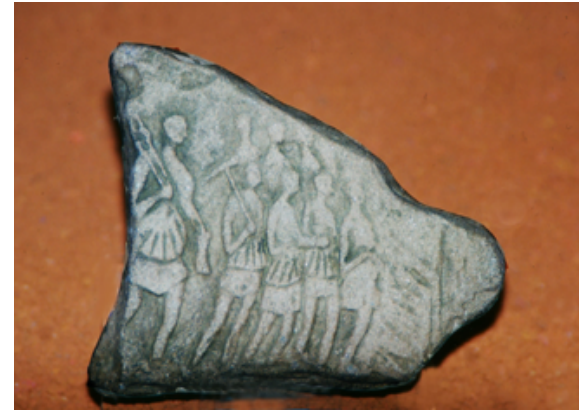

Grabado. Mineros romanos según una estela encontrada en Linares y conservada en el Deutsches Bergbau-Museum de Bochum, Alemania. Reproducción del museo Minero de Riotinto | foto Francisco J. Aute, autor de todas las imágenes de artículo si no se indica lo contrario
Creemos que en buena parte del mundo nadie necesita explicaciones sobre qué es o dónde está Sierra Morena. Las tradiciones más antiguas situaron en ella las batallas que enfrentaron a dioses y titanes, sobreviviendo de estos Gárgoris que tuvo un hijo, Habis, del que quiso deshacerse aunque el niño sobrevivió milagrosamente alimentado por las fieras. Lo que no es sino el mismo mito circunmediterráneo que encontramos en por ejemplo Grecia con Edipo, Ciro en Asia Menor, en Egipto con Osiris y Moisés o en Roma con Rómulo y Remo. Finalmente Habis consiguió ser aceptado por Gárgoris, sucediéndole como rey, y enseñó a los humanos la agricultura, la ganadería y los rudimentos de la minería, minería que dada la riqueza metalífera de su tierra, Tartesos, no tardó en extenderse y atraer comerciantes como griegos, fenicios o celtas que dejaron aquí su impronta cultural.

La Sierra Morena es una de las unidades geológicas en que se subdivide la Península Ibérica y, por decirlo así, viene a ser donde la gran llanura castellano-manchega se "derrama" hacia la extensa depresión de la cuenca bética, la antigua al-Ándalus. Sierra Morena como accidente geográfico se extiende por Jaén, Córdoba y Extremadura desde donde baja hasta Huelva penetrando también en Portugal, motivo por lo que geológicamente es conocida como Ossa-Morena. Esta Ossa-Morena no es geológicamente uniforme y presenta algunas zonas de cizallas y de grandes fallas deslizantes, aunque inactivas ya hace millones de años. En Ossa-Morena podemos encontrar principalmente tres tipos de formaciones fusionadas por la activa orogenia devónica y más tarde por el muy abundante vulcanismo y magmatismo que ocupó casi todo el carbonífero inferior hace sólo poco más de trescientos millones de años.

La teoría más aceptada y que explica de manera fundamentada y rigurosa la formación de las mayores áreas de Sierra Morena fue formulada hace unos años por el eminente geólogo holandés Robert H. Wagner Boon afincado en Córdoba desde hace tiempo y considerado como el paleobotánico vivo más eminente. R. Wagner ha podido demostrar, principalmente a través del estudio de las floras carboníferas y anteriores, en estudios avalados por muchos miles de sondeos durante largas campañas, que una gran parte del los actuales oeste y sur peninsular conformaron una placa tectónica situada aproximadamente al sur de Inglaterra y oeste de Francia y que fue derivando hasta chocar y encajarse en la península aproximadamente desde la zona de Oporto hasta el final de la actual Sierra Morena, con especial contundencia en la zona norte de Córdoba, el valle del Guadiato, donde dio lugar a una gran falla deslizante entre ambas placas tectónicas que durante millones de años estuvo activa hasta su asentamiento definitivo.

Este tremendo "esfuerzo" orogénico provocó numerosos fenómenos de vulcanismo que acompañados de los consecuentes procesos hidrotermales rellenaron la sierra de todas clases de minerales mayormente en forma de depósitos y bolsadas metalíferas. 
Desde que comenzaron a aprovecharse los metales en épocas prehistóricas e históricas, realmente hasta hace apenas una cincuentena, por toda la sierra los mineros explotaron principalmente los abundantes yacimientos que a lo largo de milenios de erosión habían quedado prácticamente en superficie a manera de numerosos afloramientos que los procesos de lixiviación atmosférica y meteorización habían vuelto particularmente ricos y fáciles de explotar. A lo largo de toda la sierra podemos encontrar socavones y útiles de estas primitivas explotaciones de fortuna. Con estos metales y con productos de la tierra se desarrolló un activo comercio con otros pueblos mediterráneos, generándose así un gran avance técnico y cultural.

En tiempos de Roma tras la invasión y asimilación de la Bética y la Beturia, las explotaciones se hicieron sistemáticas bien a nombre de particulares 0 bien a cargo de empresas o sociedades constituidas a tal fin incorporando así los muchos adelantos mineros de la ingeniería romana. Precisamente la familia cordobesa de los Mario se hizo casi con el monopolio de las factorías de Córdoba y Jaén donde los codiciados plomo, cobre, plata y oro "fluían" abundantemente. Era época de Tiberio y el hispano romano Sexto Mario había acumulado ya tal fortuna que los montes de la sierra se conocían como "los montes de Mario" o Mons Mariorum. De este Mariorum, y no de su tono frecuentemente pardo, procede el actual apelativo de la Sierra Morena. A sólo unos quince kilómetros de Córdoba podemos encontrar el topónimo de Cerro Muriano allí donde Mario tuvo unas muy ricas minas de cobre, plata y oro. También otros, como los varios Mairena jalonados por la sierra, son igualmente topónimos originados en los Mario. La inmensa fortuna de Sexto Mario provocó su fin a manos del avaro Tiberio que, tras ejecutarlo, se incautó de ella.

El trabajo minero tal vez sea el que más impacto paisajístico produce allí donde se ejecuta pues necesita de al menos cinco elementos indispensables
Ruinas y excavaciones de lasa minas de cobre de principios del siglo XX. Cerro Muriano (izquierda)

Gran socavón de tiempos romanos para extraer el mineral de cobre y plata. Cerro Muriano (abajo)
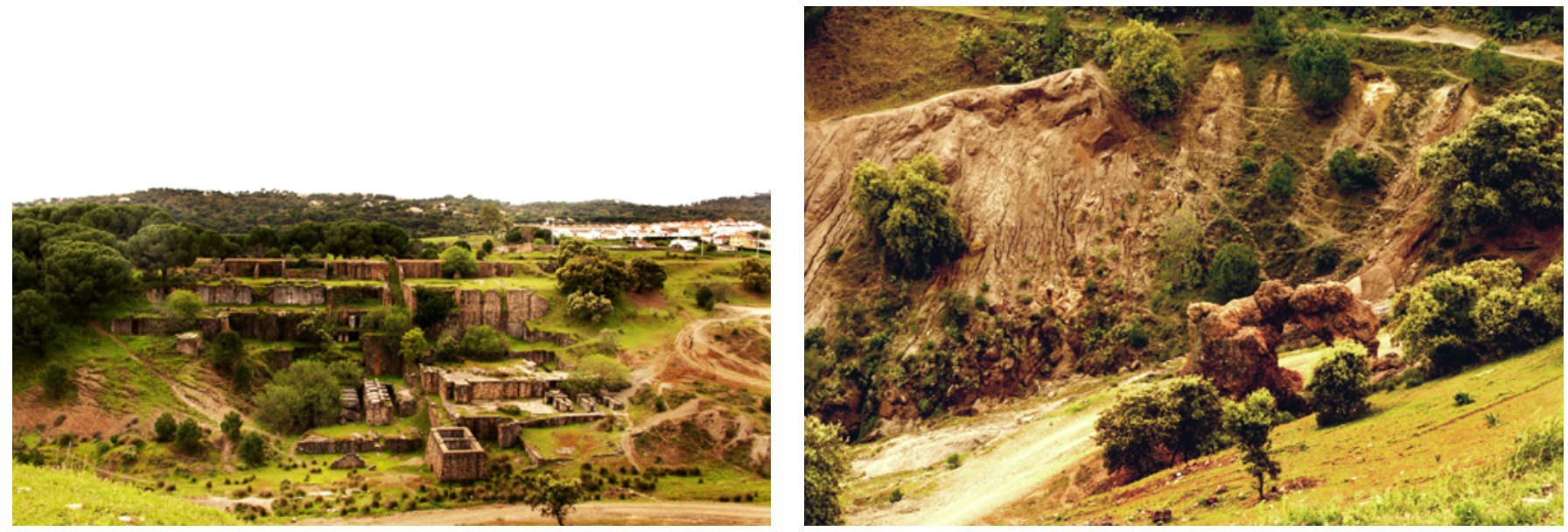


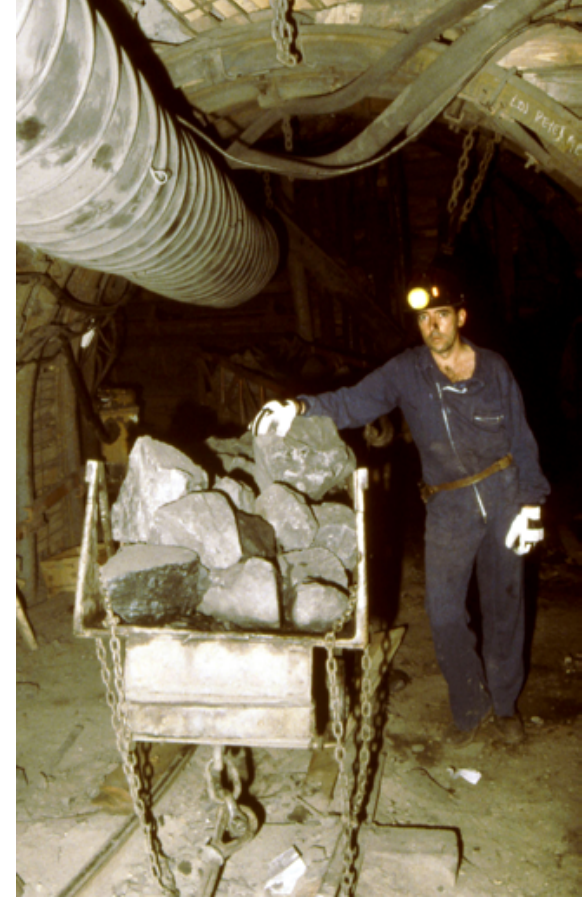

Minero en una galería de las labores del Pozo María Peñarroya-Pueblonuevo (Córdoba)

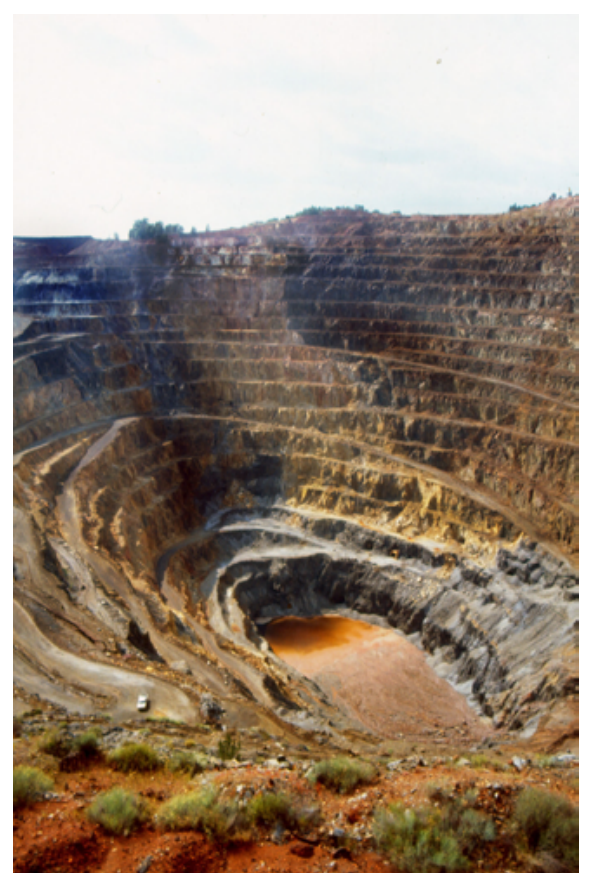

Vista de la famosa gran explotación de Riotinto principal depósito de mineral explotado para su desarrollo: unos tajos, socavones, pozos y galerías donde arrancar el mineral; una serie de albercas o diques para acumular el agua imprescindible para el lavado y tratamiento del mineral; hornos para fundir y edificios permanentes de administración y almacenes para maquinaria, repuestos y útiles; además de establos para las caballerías absolutamente necesarias en las explotaciones. En muchos casos encontramos también poblados para alojar los mineros y sus familias que, aunque no siempre, por lo general solían ser esclavos. Tampoco faltaban alojamientos de más calidad para propietarios o administradores. Finalmente en toda mina había escombreras donde se apilaban la ganga y los estériles extraídos y que son hoy día los que mejor nos indican la situación de antiguas explotaciones, además de la pervivencia frecuente de algunas construcciones.

De todos estos siglos de minería en que se trabajaron duramente las entrañas de la sierra aún quedan importantes vestigios. Los más impresionantes sin duda son las minas de Riotinto y toda la comarca del Andévalo de las que se piensa que su explotación pudo comenzar hace casi cuatro mil años. Aquí encontramos a lo largo de varios kilómetros una drástica actuación sobre el paisaje. Aparte del archiconocido socavón en forma de embudo hay multitud de pozos, como el Alfredo, que horadan el paisaje todo y varios kilómetros a lo largo del río Tinto que están modelados por balsas de lixiviación y concentración del mineral. La propia manera de preparar el mineral para su fusión mediante un proceso de reducción al aire libre (teleras) para eliminar el azufre generó una permanente lluvia ácida que arrasó el paisaje y la salud de los paisanos llegando a haber sublevaciones que costaron muchas vidas. Otro aspecto decisivo que modeló abruptamente el paisaje fueron los millones de toneladas de tierra que fueron movidas para descubrir los filones, llegando al extremo de incluso demoler pueblos enteros para facilitar el avance de la mina.

Otro espectacular ejemplo, revelador de la poderosa influencia de la minería en el paisaje, es el cerro del Hierro en Constantina. La rica zona plúmbica y argentífera a lo largo de Constantina, San Nicolás del Puerto, Alanís, Guadalcanal, etc. ya fue explotada por los romanos aunque que toparon con la dificultad de un nivel freático muy somero que paralizó muchos trabajos de envergadura en distintas épocas al no poder con los acuíferos.

Aquí mismo se encuentra un excepcional enclave geomorfológico, que tras la intervención humana a lo largo de un siglo ha dejado un espectacular paisaje difícilmente repetible y que no puede por menos que sorprendernos por su belleza en volúmenes y coloridos.

Un conjunto de acontecimientos fue necesario que se combinasen en el cerro del Hierro para llegar a tener su espectacularidad actual. Hace cientos de millones de años y bajo un clima tropical, la erosión se cebó en un macizo 
calizo torneando las agujas, mogotes, simas y corredores propios de las formaciones kársticas. Esta formación se vio más tarde sumergida en aguas con abundante contenido en iones de hierro que precipitando en forma de óxidos e hidróxidos rellenaron el karst.

Las sucesivas labores mineras para beneficiar los minerales férricos, dejaron al descubierto, después de tantos millones de años, las sobrecogedoras formaciones del paleokarst que con sus pináculos grisáceos y los fantasiosos volúmenes de los mogotes y mega agujas, arropadas de mantos ocres de oligisto y hematíes conforman uno de los paisajes más singulares de toda la sierra.

Parecidos procesos kársticos coincidieron en la formación de la mina de la Jayona en Fuente del Arco, Badajoz, apenas a unos metros del límite con Andalucía y que procuraba un mineral de hierro tan puro que casi sin necesidad de concentrarlo en bocamina podía usarse directamente como fundente en los hornos de plomo y pirita de Peñarroya-Pueblonuevo, Córdoba. La importancia del mineral de la Jayona llegó a hacer que el ferrocarril propio que tendió la Sociedad Minera y Metalúrgica de Peñarroya para comunicar sus minas de plomo de la campiña sur de Extremadura y además ahorrarse muchos reales en transporte hasta los puertos de Málaga o Sevilla en lugar de terminar en un lugar más comunicado y muy cercano como la ciudad de Llerena, Badajoz, finalizase en Fuente del Arco para descargar allí el plomo industrial y cargar el fundente de hierro. La explotación de la Jayona, por motivos económicos y políticos, prorpocionó unos años de bastante bonanza a una población campesina empobrecida por los latifundios.

Más que nada por fraudes contables y falta de inversión en el laboreo la explotación vino a cesar, hace aproximadamente un siglo, dedicándose la población de Fuente del Arco a desmantelar y achatarrar sus instalaciones, lo que impidió retomar su explotación. Es muy destacable que esta mina, perforada en roca sólida gracias al trabajo y el empeño del Ayuntamiento de Fuente del Arco y el apoyo de la Junta de Extremadura ha sido acondicionada para su visita, visita que resulta en extremo cómoda, un paseo depara grandes bellezas unas naturales y otras producto del trabajo del hombre.

Sin espacio para detenernos en paisajes tan marcados por la minería como los de la sierra Albarrana, Linares, la Carolina, el Centenillo, Rodalquilar, Macael o el Valle de los Pedroches y otros de menor envergadura, necesariamente se impone hablar de la cuenca carbonífera de Peñarroya, Belmez y Espiel, aún no siendo una ésta continuidad geológica, puesto que está formada por tres principales yacimientos carboníferos, encontrándose en sus entornos grandes manchurrones de hulla, muchos sin identificar. Los yacimientos explotados se extienden a lo largo de más de cuarenta kilómetros desde las inmediaciones de Fuente Obejuna, Córdoba, hasta las últimas

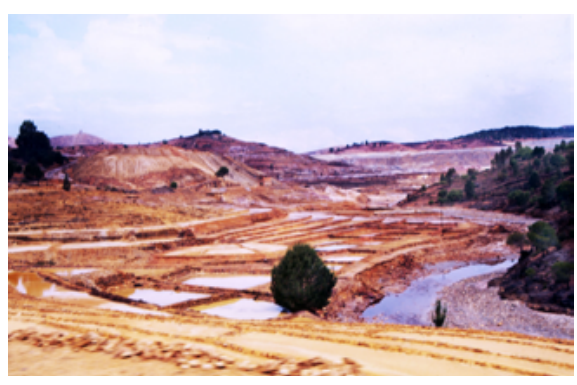

Balsas de lixiviación que aún envenenan enormes extensiones de tierra. Rio Tinto

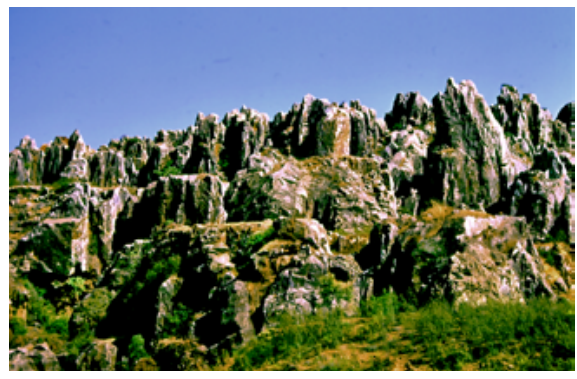

Mogotes del paleokarst del cerro del Hierro (provincia de Sevilla)

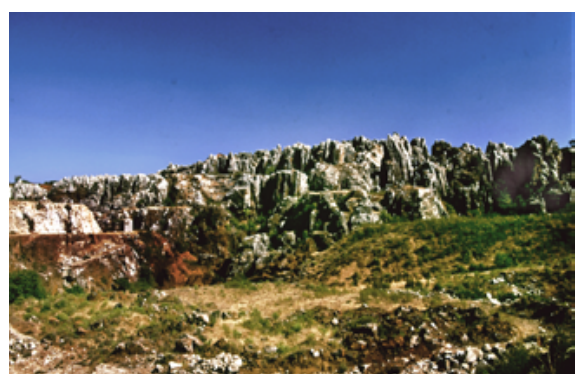

Mogotes y agujas con capas de oligisto. Cerro del Hierro

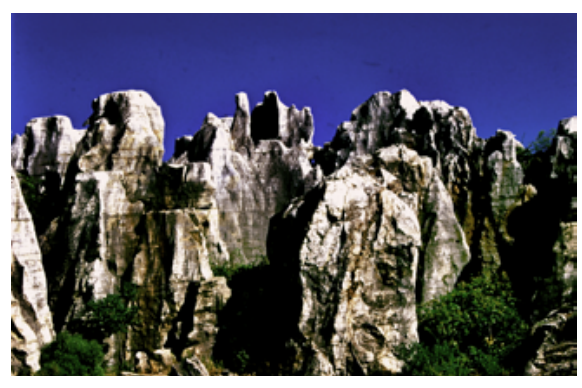

Megaagujas y simas veteadas de oligisto y hematíes. Cerro del Hierro 


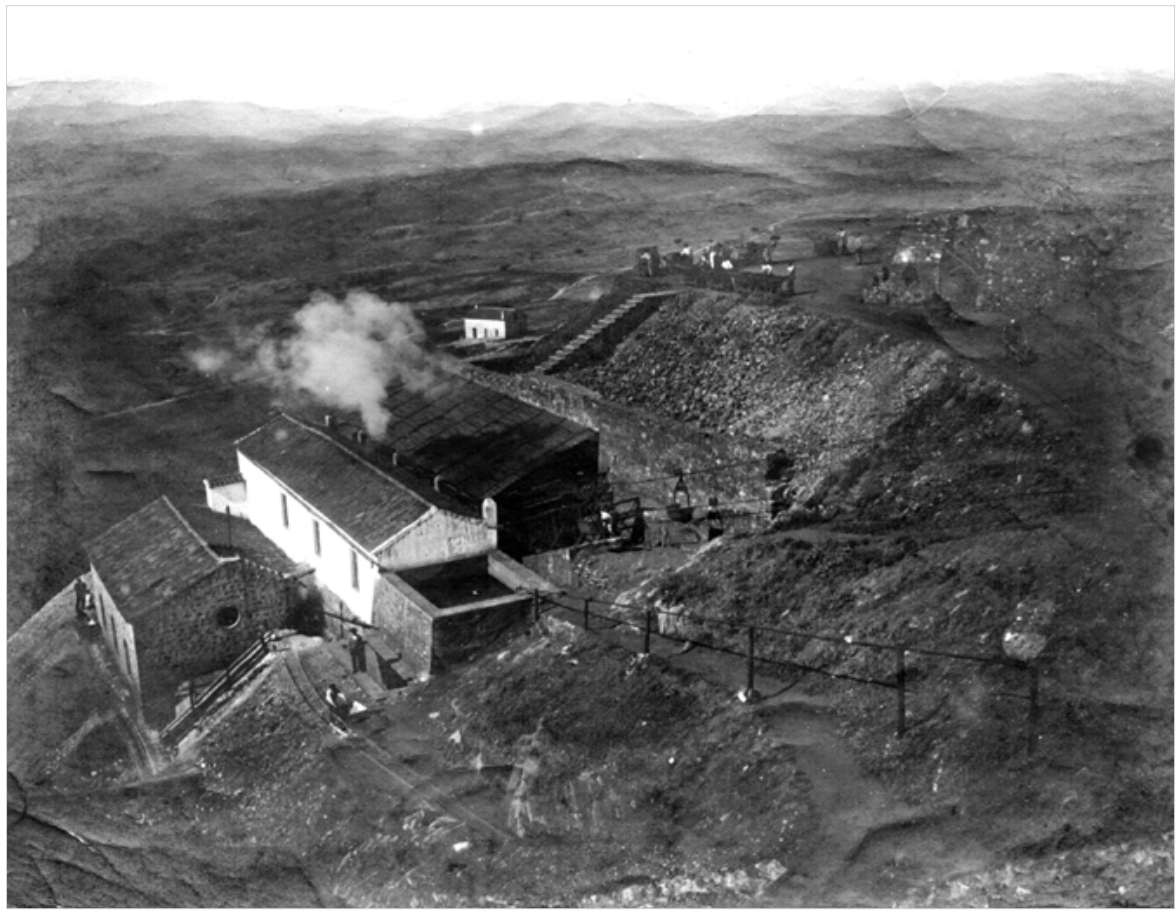

Instalaciones de la mina a finales del sigo XIX. Mina de la Jayona | fuente Archivos de la mina (Anónimo)

explotaciones que estuvieron activas en la Ballesta siendo este el final de la cuenca conocida, no muy lejos de Córdoba.

El carbón fue descubierto en el Guadiato, en Espiel, por el capataz de minas don Carlos de la Garza en el verano de 1788 y a partir de ahí se abrieron varias minas en Peñarroya y Belmez tendentes a alimentar la "máquina de fuego" instalada para el desagüe de las minas de azogue de Almadén. La ausencia de carreteras o caminos de cualquier clase y la invasión francesa paralizaron los trabajos hasta que, a mitad del siglo XIX, el clamor nacional por tener un carbón propio y barato para no depender del inglés, así como los intereses de las compañías ferroviarias que se aproximaban a la zona, reavivaron los trabajos que no cesaron ya en los ciento cincuenta años siguientes. Pronto el capital fue todo de nacionalidad francesa constituyéndose la Sociedad Minera y Metalúrgica de Peñarroya en 1881.

Como la explotación del carbón no resultó especialmente rentable por los temerarios costes ferroviarios impuestos por las compañías, se concentró en Pueblonuevo del Terrible, hoy Peñarroya-Pueblonuevo, todo el tratamiento y fundición del plomo producido en las campiñas bajas de Badajoz, por donde, desde 1895, discurría el ferrocarril de vía métrica de esta empresa, ampliado sobre 1925, sorteando grandes dificultades hasta Puertollano, Ciudad Real, enlazando así las explotaciones de plomo del valle de los Pedroches, el valle de Alcudia y el Horcajo. El mineral concentrado en bocamina se traía a 
Peñarroya donde era fundido y separado de otros metales que regularmente suelen estar asociados a él como la plata, el cobre, bismuto, zinc, etc. Luego se expedía a Francia vía marítima desde Sevilla.

La Sociedad Minera y Metalúrgica de Peñarroya, más humana o más informada que sus colegas y socios de Riotinto, acabó con las lluvias ácidas sustituyendo el sistema de teleras para calcinar el mineral por hornos continuos, recogiendo los gases que se producían en cámaras de plomo para generar ácido sulfúrico, también nítrico, lo que dio lugar a una muy importante industria química orientada a la agricultura: con fosfatos (del Sáhara), superfosfatos, sulfato de hierro, de cobre, etc. Tanto que tuvieron que instalarse diversas industrias auxiliares, como fábricas de sacos, para dar salida a esta producción cuya demanda sobrepasaba los límites nacionales. Parece ser que también aquí, si hacemos caso a publicaciones de la época, en la fábrica de óleum (gas sulfúrico fumante) se produjo iperita o gas mostaza. Si no fue así sí es seguro, por testimonios de la época, que se desarrollaron algunos de sus componentes básicos.

En cualquier caso, y para cubrir una cuenca de tamaña longitud donde el carbón solía presentarse en importantes bolsadas y lentejones, se abrieron por doquier pequeñas y grandes explotaciones que han dejado el paisaje sembrado de construcciones derruidas, negras escombreras o edificaciones de mayor envergadura. Cuando tras la Segunda Gran Guerra tanto el carbón como el plomo dejaron de ser minerales estratégicos comenzó el declive de las explotaciones. En los años ochenta del pasado siglo los beneficiarios consiguieron darse cuenta de que las explotaciones a cielo abierto eran más baratas y productivas que las de interior, aunque el producto fuese de peor calidad.

Desaparecieron las minas convencionales, el pozo María fue la última, y quedaron algunas grandes depresiones de muchos metros de longitud y profundidad en los lugares donde se explotó a cielo abierto.

En los años ochenta de la pasada centuria vieron la luz las leyes que obligaban a la restitución de los terrenos expropiados, lo que se ha interpretado de muy diversas formas, la principal ha sido recubrir las escombreras con la tierra vegetal retirada antes y proceder a la repoblación botánica con especies autóctonas.

Justamente ahora se está en pleno tira y afloja entre la empresa Endesa, propietaria de muchos de los antiguos terrenos mineros y las poblaciones de la cuenca, pues Endesa ha puesto a la venta para su desguace y desmantelamiento varios pozos e instalaciones como el pozo María, muy reciente e ideal por su conservación para poder instalar en sus edificios anejos los archivos, litoteca y otras instalaciones con las que la Fundación Patrimonial

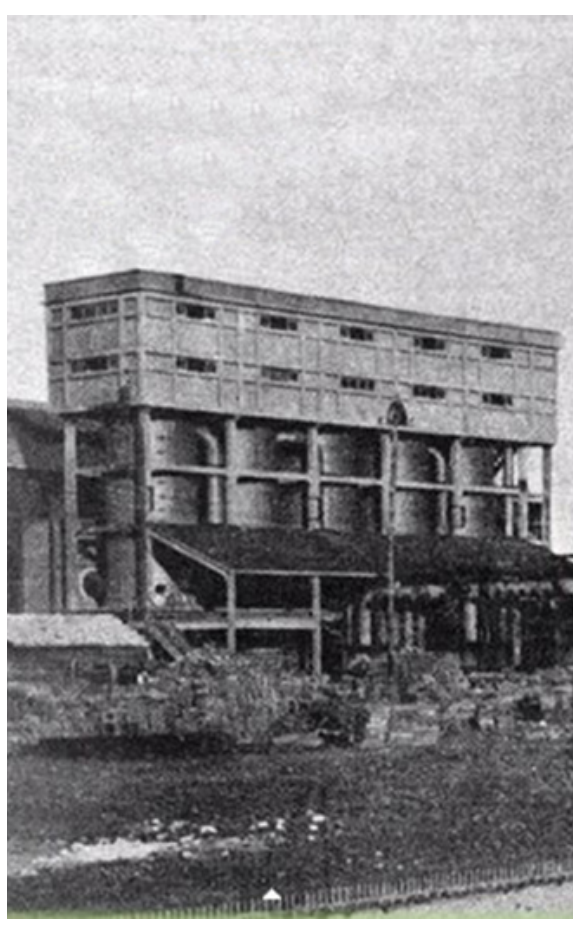

Fábrica de óleum en 1927, hoy desaparecida. Fotografía de un almanaque publicitario de la época | Archivos del autor (Anónimo) 


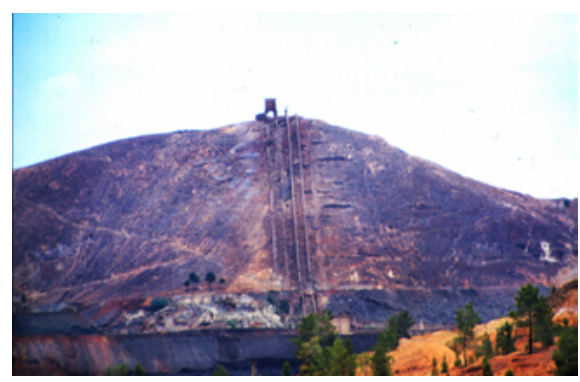

Conductos de gases sulfurosos y chimenea. Esos gases producían abundantes lluvias ácidas. Riotinto (Huelva)

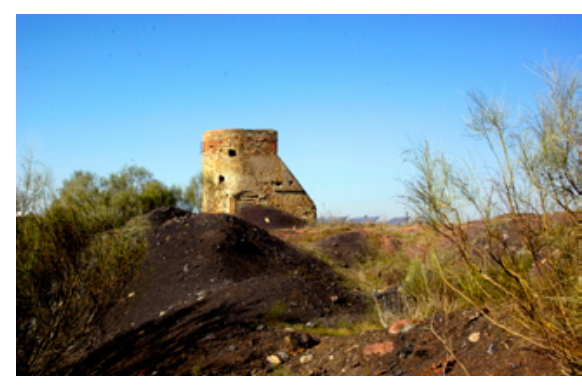

Peñarroya-Pueblonuevo. Restos de un castillete de mampostería que tuvo diversos usos secundarios tras explotar su carbón. Mina la Terrible

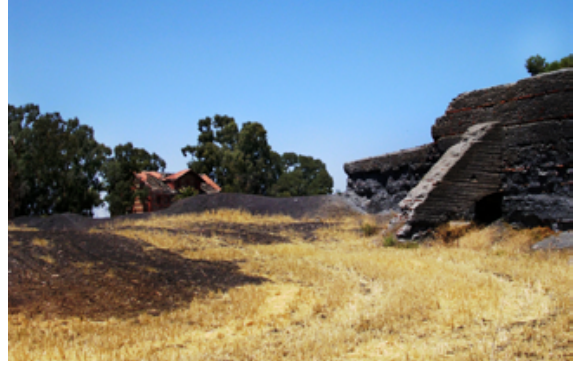

Degradación del paisaje tras el abandono de las explotaciones. Peñarroya-Pueblonuevo (Córdoba). Mina la Calera

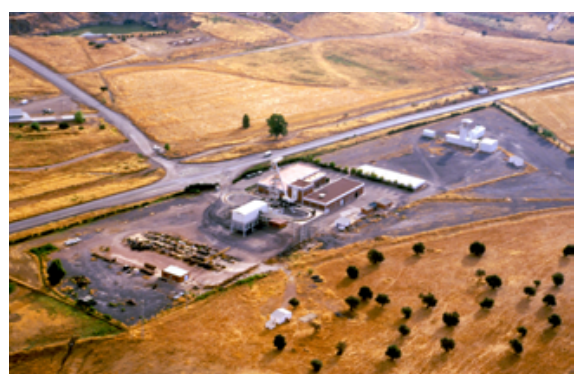

Vista aérea de la mina María la última que se abrió en Europa. Con ella cesó la minería de interior en la comarca del Guadiato. Peñarroya-Pueblonuevo

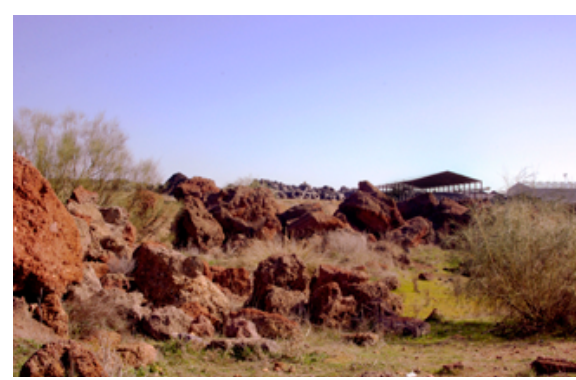

Paisaje degradado por escombreras y escoriales restos de la actividad minera e industrial. Barranco de San Miguel de Peñarroya-Pueblonuevo

del alto Guadiato pretende preservar miles de planos, informes geológicos y resto de información de carácter variado que está en riesgo de desaparecer.

Para finalizar, si queremos realmente saber cómo la minería ha afectado lo largo de milenios el paisaje de nuestra Sierra Morena lo ideal sería desplazarnos a lo lago de ella a través de algún medio aéreo con la seguridad de que en cualquier rincón, por apartado que esté, encontraríamos las cicatrices de una minería que durante milenios ha conformado y sigue conformando nuestro paisaje serrano. En el mismo morral podríamos incluir a los varios desaparecidos ferrocarriles, desde su invención unidos siempre a la minería. 


\section{BIBLIOGRAFÍA}

- ACTAS del simposio sobre patrimonio geológico y minero. IV Sesión Científica de la Sociedad Española para la Defensa del Patrimonio Geológico y Minero. Belmez, 28, 29 y 30 de octubre de 1999. sl: sn, 1999

- AA.VV. (1994) L'héritage des gueules noires: de l'histoire au patrimoine industriel: Wallonie, Limbourg, Nord-Pas-deCalais, Aix-la-Chapelle. Charleroi: Archives de Wallonie, 1994

- AA.VV. (1981) Libro del centenario. Madrid: Sociedad Minera y Metalúrgica de Peñarroya, 1981 (Edición numerada)

- AUTE, F. J.; CARRASCO, Y. (2006) Arquitectura industrial en Peñarroya-Pueblonuevo a finales del siglo XIX y principios del XX. Peñarroya-Pueblonuevo: Ayuntamiento de Peñarroya-Pueblonuevo, 2006

- AUTE, F. J. (1999) Breve historia de la minería en la cuenca de Peñarroya y Belmez. Belmez: Escuela Politécnica de Belmez; Seminario Antonio Carbonell, 1999

- AUTE, F. J. (2008) Expediente del patrimonio histórico ferroviario en Peñarroya-Pueblonuevo. Informe. Delegación de Cultura, Junta de Andalucía, 2008

- AUTE, F. J.; PAYER, M. I. (2009) Expediente de patrimonio histórico minero de Peñarroya-Pueblonuevo. Informe. Delegación de Cultura, Junta de Andalucía, 2009

- AVERY, D. (1985) Not on Queen Victorias's Birthday. Londres: RTZ. Services Limited, 1985

- CALVO PÉREZ, B.; GONZÁlEZ DEL TÁNAGO CHANRAI, J.; GONZÁLEZ DEL TÁNAGO Y DEL RÍO, J. (1996) Los minerales y la minería de la sierra albarrana y su entorno. Madrid: Enresa-Promed, 1996

- CALVO REBOLLAR, M. (2003) Minerales y minas de España. Álava: Arabako Foru Aldundia; Diputación Foral de Álava, 2003, Vol. I y II.

- CARBONELL Y TRILLO-FIGUEROA, A. (1947) Criaderos de plomo de la provincia de Córdoba. Tomos I-VI. (Remitido al) Instituto Geológico y Minero de España, 1947

- CHAStAgnARET, G. (2000) L'Espagne, puissance minière: dans l'Europe du XIXe siècle. Madrid: Casa de Velázquez, 2000

- COLL MARTíN, S.; SUDRIÀ I TRIAI, C. (1987) El carbón en España 1770-1961. Empresa Nacional Carbonífera del Sur, S. A. Madrid: Ediciones Turner, 1987

- JIMÉNEZ HERNANDO, J. M. (2011) 1961-2011 de la carbonífera a Encasur, 50 años de travesía minera. Santander: Cantabria Tradicional S.L., 2011

- LÓPEZ MOREL, M. A. (2005) La casa Rothschild en España. Madrid: Marcial Pons, Ediciones de Historia, 2005
- GAMBOA, F. X. DE (1761) Comentarios a las ordenanzas de minas. Oficina de Joachin Ibarra. Madrid, 1761

- catálogo de cartografía histórica de Córdoba. Instituto de Cartografía de Andalucía. Junta de Andalucía, Consejería de Obras Públicas y Transportes, 2002

- Penco VAlenzuela, F. (2010) Historia de la minería en Córdoba, Cerro Muriano sitio histórico. Córdoba: Editorial Almuzara, 2010

- PÉrez de PERCEVAl VERDE, M. Á.; LÓPEZMORELL, M. Á; SÁNCHEZ RODRÍGUEZ, A. (2006) Minería y desarrollo económico en España. Instituto Geológico y Minero de España. Madrid: Editorial Síntesis, 2006

- RUIZ BALLesteros, E. (1998) Minería y poder. antropología política en Riotinto. Diputación Provincial de Huelva. Huelva 1998.

- VAQUERIzo GIL, D. (1994) Minería y metalurgia en la España prerromana y romana. Córdoba: Diputación de Córdoba, 1994

Consulta de:

> Numerosa bibliografía de Antonio Carbonell y TrilloFigueroa sobre minería y explotaciones mineras de distintos lugares de Sierra Morena, copias disponibles en el Seminario Carbonell de la Escuela Politécnica de Belmez.

> Libros de actas, contabilidad, matrices de acciones, títulos de propiedad etc., de la Compañía Especial Minera Bético Manchega. Originales de 1840-1910. Archivo del autor. 